\title{
EXPERIMENTAL STUDY OF MIXED MODE CRACK PARAMETERS IN HIGH PERFORMANCE CONCRETE
}

\author{
T. Santhi Sagar $M^{1}$, Y.Murali Krishna $M^{2}$, Ch.N.Satish Kumar ${ }^{3}$ \\ ${ }^{1}$ Assistant Professor, Department of Civil Engineering, Bapatla Engineering College, Bapatla-522101, India \\ ${ }^{2}$ Assistant Professor, Department of Civil Engineering, Bapatla Engineering College, Bapatla-522101, India \\ ${ }^{3}$ professor, Department of Civil Engineering, Bapatla Engineering College, Bapatla-522101, India
}

\begin{abstract}
In this paper an experimental investigation was carried out to study the fracture behavior of plain high performance concrete beams subjected to three point bending. In this investigation to study the effect of stress intensity factor and Fracture energy of concrete beams of various sizes with constant position of notch from center of beam and notch depth ratios. It was found that the stress intensity factor and fracture energy increases with the increasing of beam sizes and decreasing the failure stresses with increasing the beam sizes.
\end{abstract}

Keywords: Stress Intensity Factor, Fracture Energy, Three Point Bending

\section{INTRODUCTION}

Concrete is often considered a heterogeneous material in engineering design and construction, yet is in reality a composite consisting of mortar matrix and aggregate inclusion phases. Upon closer inspection, voids are apparent, as the cement paste is actually a mixture of different types of crystalline structures at various degrees of hydration with trapped and entrained air voids. Most researchers simplify concrete as a two-phase composite consisting of mortar and aggregate; to complete the model, defects known as 'microcracks' are introduced in the system. The failure process is initiated when minute bond cracks format mortar-aggregate interfaces, while small cracks may also occur in the mortar and aggregate phases separately. Fracture of these microcracks gives concrete the semblance of ductility; it is the brittle propagation of many microcracks that form a semi-ductile propagation of a microcrack and ultimately lead to material failure. In fracture mechanics terminology there are three different cracking modes defined: (i) mode I- opening mode, (ii) mode II - shearing mode and (iii) mode III- tearing mode. At the macro scale level they describe three independent kinematic movements of the upper and lower crack surface with respect to each other and are sufficient to define all possible modes of crack propagation in an elastic material. Of course, at the micro scale the stress distribution is much more complex and at such a level modes of fracture have no sense. As far as concrete is concerned, mode I is a relatively clear type of crack propagation. On the contrary, mode II and III are complex failure modes, which can hardly be realized in an experiment. In these modes the stress normal to the crack surface need to be approximately zero and only in-plane shear stress should exist. Even when these conditions can be realized, due to the complexity of the concrete structure, over a concrete crack surface a combination of different stresses exist (shear, tension, compression and bending). Although the resulting stress may be in-plane stress (shear), complex stress-strain conditions on a crack surface make the identification of mode II and III fracture parameters extremely difficult. Moreover, the question arises whether in a sense of linear elastic fracture mechanics these two failure modes even exist. The similar complex combination of stresses exists for mode I fracture type as well, however, the stress and strain perpendicular to the crack surface dominate at this fracture type. large number of experimental results of crack initiation and propagation in mixed mode on notched beams are based on the Iosipescu geometry (Iosipescu, 1967; Arrea and Ingraffea, 1982; Bažant and Pfeiffer, 1986; Biolzi, 1990; Bocca et al., 1991; Schlangen, 1993a, b; Swartz and Taha, 1990) and the results developed in the RILEM 89-FMT Committee (Ballatore et al., 1990; Bocca et al., 1990), among others. Other sets of experimental results are based on the three point bend of notched beams with eccentric notch: (Guo et al., 1994a,b; Jenq and Shah, 1988; Swartz et al. 1988a), among others. Moreover, there are experimental results developed on notched cylinders (Barr et al., 1989) and double notched prismatic specimens (Bažant and Pfeiffer, 1986; Schlangen, 1993a; Barr and Deradj, 1990; Davies, 1989). The advance has been important, but some aspects need to be studied in depth $[1,2]$.

In the present paper, our main attention is to study the influence of eccentrically placed notch of high strength concrete beams of various sizes and high performance concrete with constant notch depth ratio with constant mix proportions on mixed mode stress intensity factor, fracture energy and failure stresses

\section{EXPERIMENTAL PROGRAM}

The experimental program was designed to study the stress intensity factor and fracture energy of plain-high strength concrete beams of size $75 \mathrm{~mm} \times 75 \mathrm{~mm} \times 350 \mathrm{~mm}$ (Span is $300 \mathrm{~mm}), 75 \mathrm{~mm} \times 150 \mathrm{~mm} \times 650 \mathrm{~mm}$ (Span is $600 \mathrm{~mm})$ and 
$75 \mathrm{~mm} \times 300 \mathrm{~mm} \times 1250 \mathrm{~mm}$ (Span is $1200 \mathrm{~mm}$ ) with eccentrically placed notch at (L/4) from mid span of the beam under a three point bending test i.e., with a central point load. The influence of eccentrically placed notch of specimens on stress intensity and fracture energy was studied on beams of varying size effects with constant mix proportions (M30).

This experimental program consists of three series of beams for each grade, namely small, medium, and large and having equal notch depth ratio (0.2) from a distance $X$. In this series ' 0.2 ' represents the notch depth ratios and ' $\mathrm{X}$ ' represents the position of notch from the center of the beam (L/4). Fig shows the schematic arrangement of the beam specimen subjected to three point bending.

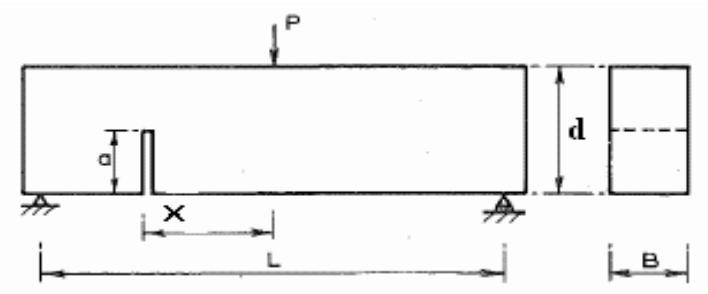

Loading configuration for mixed mode test

\section{MATERIAL DETAILS:}

Ordinary Portland cement (OPC) of 53 grade conforming to IS 8112:1989 with specific gravity of 3.15 was used in Concrete mix [6]. Fine aggregate conforming to Zone II of IS 383:1970 was used[7].Crushed coarse aggregate passing through $20 \mathrm{~mm}$ sieve and retained on $10 \mathrm{~mm}$ sieve(100\%) with specific gravity 2.7 was used. Robo Sand or crusher dust obtained from local granite crushers was used in concrete and also GGBS is used in concrete.

Table: 4 details of materials for 1 cubic meter of concrete

\begin{tabular}{|l|l|l|l|l|l|}
\hline $\begin{array}{l}\text { Grade } \\
\text { of } \\
\text { concre } \\
\text { te }\end{array}$ & $\begin{array}{l}\text { Mix } \\
\text { Proportion }\end{array}$ & $\begin{array}{l}\text { Water } \\
\text { wt. } \\
(\mathbf{k g})\end{array}$ & $\begin{array}{l}\text { Ceme } \\
\mathbf{n t} \\
\mathbf{w t} .(\mathrm{k} \\
\text { g) }\end{array}$ & $\begin{array}{l}\text { Weig } \\
\text { ht of } \\
\text { FA } \\
\text { (kg) }\end{array}$ & $\begin{array}{l}\text { Weig } \\
\text { ht of } \\
\text { CA } \\
(\mathbf{k g})\end{array}$ \\
\hline M30 & $\begin{array}{l}0.46: 1: 1.26: \\
3.12\end{array}$ & 191.6 & 416.5 & 525.7 & $\begin{array}{l}1300 . \\
3\end{array}$ \\
\hline
\end{tabular}

Table 5: Mechanical properties of concrete

\begin{tabular}{|c|c|c|c|c|}
\hline $\begin{array}{l}\text { Grad } \\
\text { e of } \\
\text { concr } \\
\text { ete }\end{array}$ & $\begin{array}{l}\% \\
\text { Robosand\&\% } \\
\text { GGBS }\end{array}$ & $\begin{array}{l}\text { Mix } \\
\text { Proportion }\end{array}$ & $\begin{array}{l}\mathbf{f}_{\mathrm{ck}} \\
(\mathrm{N} / \mathbf{m} \\
\left.\mathbf{m}^{2}\right)\end{array}$ & $\begin{array}{l}\mathbf{f}_{t} \\
(\mathrm{~N} / \mathrm{m} \\
\left.\mathbf{m}^{2}\right)\end{array}$ \\
\hline \multirow{4}{*}{ M30 } & R-0\%-G-0\% & \multirow{4}{*}{$\begin{array}{l}0.46: 1: 1.26: \\
3.12\end{array}$} & 37.1 & 3.2 \\
\hline & $\mathrm{R}-25 \%-\mathrm{G}-25 \%$ & & 40.12 & 3.6 \\
\hline & R-30\%-G-50\% & & 48.89 & 4 \\
\hline & R-50\%-G-50\% & & 46.79 & 4.1 \\
\hline
\end{tabular}

\section{CASTING}

Cubes of $150 \mathrm{~mm}$ size were used to determine the compressive strength of concrete. Cylinders with $150 \mathrm{~mm}$ diameter and $300 \mathrm{~mm}$ length were used to determine the splitting tensile strength of concrete. Specially made wooden specimens are used for casting prisms. The moulds were tightly fitted and all the joints were sealed by plaster of Paris in order to prevent leakage of cement slurry through the joints. The inner side of the moulds was thoroughly oiled before going for concreting. The mix proportions were put in miller and thoroughly mixed.

The prepared concrete was placed in the moulds and is compacted using needle \& plate vibrators. The same process is adopted for all specimens. After specimens were compacted the top surface is leveled with a trowel. The specimens were removed from the moulds after 24 hours of casting, the specimens were placed in water for curing. All the specimens were water cured for 28 days. After removing the specimens from the curing tank they are allowed to dry for some period. They were cleaned with cotton waste to remove the dust particles. All the specimens were white washed with white cement. For notch, beams were cut with a marble cutter in to the hardened concrete. In this experimental investigation a total of eighteen concrete beams were casted.

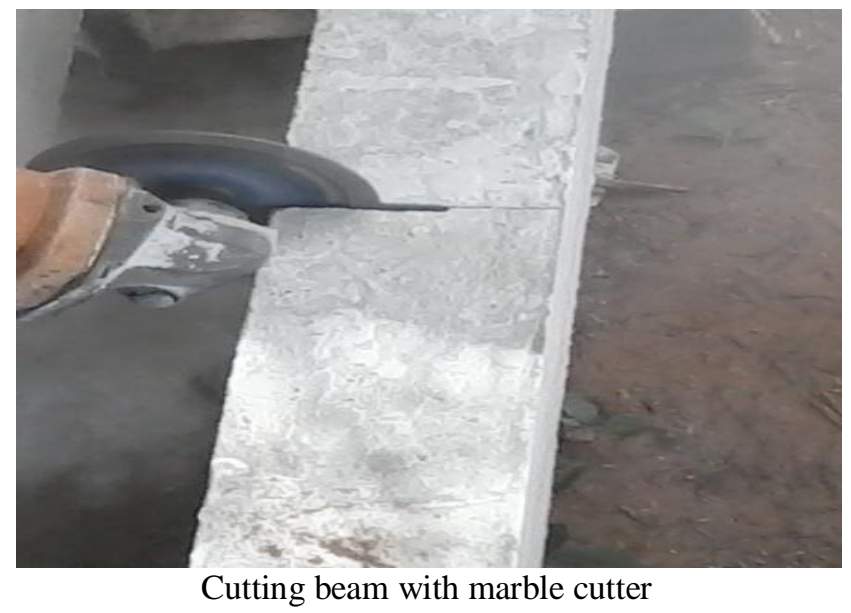

\section{TEST SETUP AND TESTING PROCEDURE}

All the beam specimens were tested on the loading frame testing Machine of 100 tons capacity under displacement rate control and cubes and cylinders on UTM. The beam specimen was kept at the center of testing machine. Beam specimens were put on roller supports exactly under the centre of the load point. For finding the compressive strength of the cube, split tensile strength of the cylinder and the modulus of rupture of the prism specimens were tested on the UTM. The specimen was placed in the machine in such manner that the load was applied on the axis of the specimen was carefully aligned at the center of the loading frame .The load was applied without shock and increased continuously at a constant rate until the resistance of the specimen to the increasing load breaks down and no greater can be sustained .The maximum load applied on the specimen was recorded. 


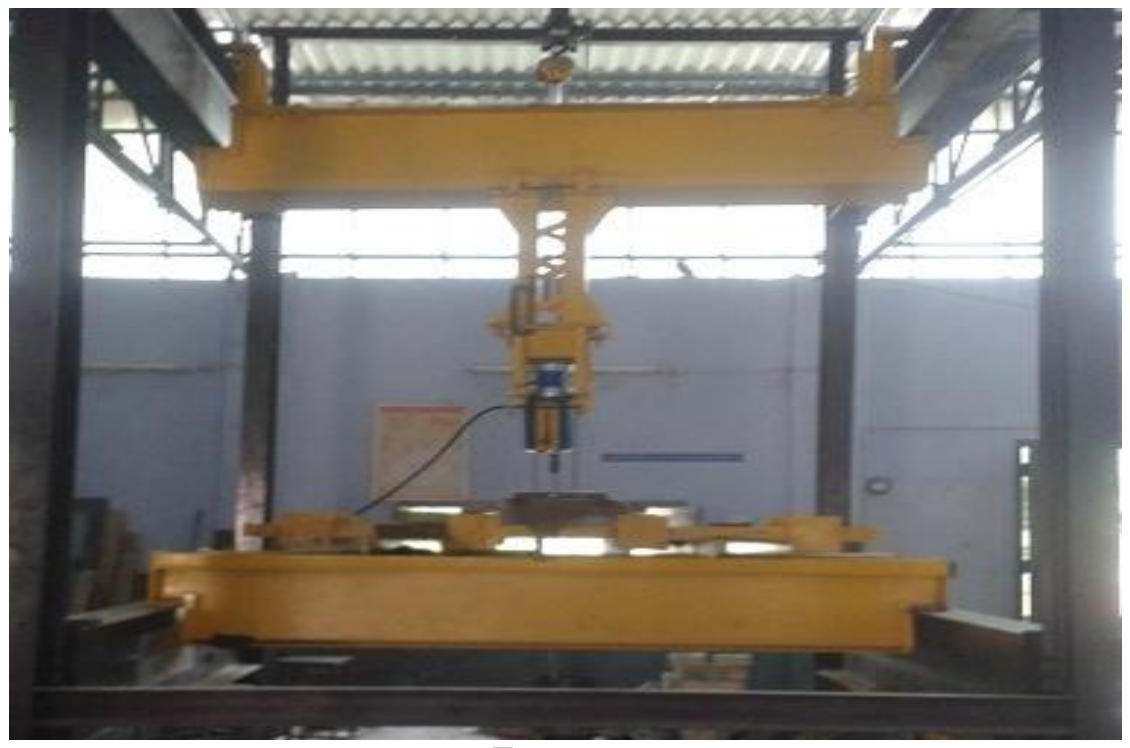

Test setup

\section{Dimensions of beam specimens in Size Effect Method}

\begin{tabular}{|l|l|l|l|l|l|l|l|l|l|}
\hline $\begin{array}{l}\text { Grade } \\
\text { of } \\
\text { concrete }\end{array}$ & Specimen & $\begin{array}{l}\text { Aggregate } \\
\text { Size } \\
(\mathrm{mm})\end{array}$ & $\begin{array}{l}\text { Length,L, } \\
(\mathrm{mm})\end{array}$ & $\begin{array}{l}\text { width,b, } \\
(\mathrm{mm})\end{array}$ & $\begin{array}{l}\text { Depth,d, } \\
(\mathrm{mm})\end{array}$ & $\begin{array}{l}\text { Span,S, } \\
(\mathrm{mm})\end{array}$ & $\begin{array}{l}\text { Notch } \\
\text { Depth } \\
(\mathrm{a} 0)\end{array}$ & a0/d & S/d \\
\hline \multirow{3}{*}{ M30 } & Small & 20 & 350 & 75 & 75 & 300 & 11.25 & 0.15 & 4 \\
\cline { 2 - 10 } & Medium & 20 & 650 & 75 & 150 & 600 & 22.5 & 0.15 & 4 \\
\cline { 2 - 10 } & Large & 20 & 1250 & 75 & 300 & 1200 & 45 & 0.15 & 4 \\
\hline
\end{tabular}

\section{Quantities of Materials}

\begin{tabular}{|l|l|l|l|l|l|l|l|l|l|}
\hline S.NO & $\begin{array}{l}\text { \% Of Robosand } \\
\text { and GGBS }\end{array}$ & $\begin{array}{l}\text { Agg. } \\
\text { Size } \\
\mathbf{m m}\end{array}$ & $\begin{array}{l}\text { Specimen size } \\
(\mathbf{m m})\end{array}$ & $\begin{array}{l}\text { Wt. of } \\
\text { water } \\
(\mathbf{K g})\end{array}$ & $\begin{array}{l}\text { Wt. of } \\
\text { cement } \\
(\mathbf{K g})\end{array}$ & $\begin{array}{l}\text { Wt. of } \\
\text { FA } \\
(\mathbf{K g})\end{array}$ & $\begin{array}{l}\text { Wt. of } \\
\text { CA } \\
(\mathbf{K g})\end{array}$ & $\begin{array}{l}\text { Wt. of } \\
\text { Robo } \\
\text { sand } \\
(\mathbf{K g})\end{array}$ & $\begin{array}{l}\text { Wt. } \\
\text { GGBS } \\
(\mathbf{K g})\end{array}$ \\
\hline 1. & R-0\%-G-0\% & 20 & $75 \times 75 \times 350$ & 0.527 & 1.147 & 1.147 & 3.582 & 0 & 0 \\
\hline & R-0\%-G-0\% & 20 & $75 \times 150 \times 650$ & 1.95 & 4.259 & 4.259 & 13.29 & 0 & 0 \\
\hline & R-0\%-G-0\% & 20 & $75 \times 300 \times 1250$ & 7.54 & 16.39 & 16.39 & 51.15 & 0 & 0 \\
\hline 2. & R-25\%-G-25\% & 20 & $75 \times 75 \times 350$ & 0.527 & 0.860 & 1.860 & 3.582 & 0.286 & 0.362 \\
\hline & R-25\%-G-25\% & 20 & $75 \times 150 \times 650$ & 1.95 & 3.194 & 4.027 & 13.29 & 1.064 & 1.342 \\
\hline & R-25\%-G-25\% & 20 & $75 \times 300 \times 1250$ & 7.54 & 12.29 & 15.51 & 51.15 & 4.097 & 5.17 \\
\hline 3. & R-30\%-G-50\% & 20 & $75 \times 75 \times 350$ & 0.527 & 0.573 & 1.013 & 3.582 & 0.573 & 0.4344 \\
\hline & R-30\%-G-50\% & 20 & $75 \times 150 \times 650$ & 1.95 & 2.129 & 3.759 & 13.29 & 2.129 & 1.611 \\
\hline & R-30\%-G-50\% & 20 & $75 \times 300 \times 1250$ & 7.54 & 8.195 & 14.47 & 51.15 & 8.195 & 6.204 \\
\hline 4. & R-50\%-G-50\% & 20 & $75 \times 75 \times 350$ & 0.527 & 0.573 & 0.724 & 3.582 & 0.573 & 0.724 \\
\hline & R-50\%-G-50\% & 20 & $75 \times 150 \times 650$ & 1.95 & 2.129 & 2.685 & 13.29 & 2.129 & 2.685 \\
\hline & R-50\%-G-50\% & 20 & $75 \times 300 \times 1250$ & 7.54 & 8.195 & 10.34 & 51.15 & 8.195 & 10.34 \\
\hline
\end{tabular}

The beam specimens were tested on the Loading Frame Machine under displacement rate control. All the beam specimens were tested under the three point bending test with the displacement rate control. A photograph of the test setup is shown in Fig 4.1. To understand the fracture behavior of plain concrete beams and High Performance Concrete beamsTthe following graphs were drawn i) Load Vs deflection. The stress intensity factor and the fracture energy and normal stresses of the beams subjected to three point bending with eccentrically placed notch at a distance (L/4) from mid span of the beam, is calculated by using the suitable equations which are mentioned below. From the graphs and Tables it was observed the Mixed Mode failure of concrete, 


\section{RESULTS AND DISCUSSIONS:}

Based on the tests on Concrete beams it can be observed that, in the case of eccentrically placed notch at a distance (L/4) from mid span of the beam, in plain concrete beams and High Performance Concrete, the first crack appeared at notch tip. The deflections were measured only up to the ultimate load and failed suddenly into two pieces.

For calculation of the stress intensity factor the following formulas are used

$$
\begin{gathered}
K_{1}=\sigma_{n} \sqrt{\pi * a_{0}} f(\alpha) \\
\sigma_{n}=C_{N} \frac{P_{u}}{b d}
\end{gathered}
$$

$a_{0}=$ Notch depth

$\mathrm{C}_{\mathrm{N}}=$ Arbitrary constant $=1.5(\mathrm{~L} / \mathrm{D})$

$f(\alpha)=\frac{1.99-\alpha(1-\alpha)\left(2.15-3.93 \alpha+2.7 \alpha^{2}\right.}{1.772(1+2 \alpha)(1-\alpha)^{3 / 2}} \quad$ For beams having geometry of $\mathrm{L} / \mathrm{D}=4$

$\alpha=$ Notch $/$ Depth ratio $=\mathbf{0 . 1 5}$

$P_{u}=$ failure load

$b=$ thickness of the beam

$\mathrm{d}=$ depth of the beam
After finding the value of stress intensity factor $K_{1}$ value then the value of the fracture energy is obtained in non linear fracture approach by the formula

$$
\begin{gathered}
G_{f}=\frac{g(\alpha)}{E A} \\
g(\alpha)=C_{N}^{2} \pi \alpha f(\alpha)^{2}
\end{gathered}
$$

E $=$ young's modulus of concrete $=5700 \sqrt{f} \mathrm{fk}$ $A=$ constant obtained from regression plot

After obtaining the value of fracture energy $G_{f}$ the brittleness number is obtained by formula

$$
\beta=\frac{d}{d_{0}}
$$

$d=$ depth of beam, $d_{0}=C / A$ taken from regression plot

\begin{tabular}{|c|c|c|c|c|c|c|c|}
\hline S.NO. & $\begin{array}{l}\% \text { Of Robosand } \\
\text { and GGBS }\end{array}$ & $\begin{array}{l}\text { Agg. } \\
\text { Size } \\
\text { mm }\end{array}$ & $\begin{array}{l}\text { Specimen size } \\
(\mathbf{m m})\end{array}$ & $\begin{array}{l}\text { Grade Of } \\
\text { Concrete }\end{array}$ & $\begin{array}{l}\text { Peak } \\
\text { Load } \\
\text { P(max }) \\
\text { KN }\end{array}$ & 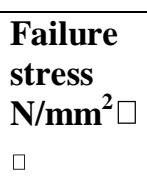 & $\begin{array}{l}\text { Stress intensity } \\
\text { factor } \\
\left(\mathbf{N} / \mathbf{m m}^{2}\right) \sqrt{ } \mathbf{m m} \\
\mathbf{K}_{\mathbf{I}}\end{array}$ \\
\hline \multirow[t]{3}{*}{1.} & R- $0 \%-\mathrm{G}-0 \%$ & 20 & $75 \times 75 \times 350$ & 30 & 5 & 5.358 & 31.439 \\
\hline & R- $0 \%-\mathrm{G}-0 \%$ & 20 & $75 \times 150 \times 650$ & 30 & 9 & 4.846 & 40.215 \\
\hline & R-0\%-G-0\% & 20 & $75 \times 300 \times 1250$ & 30 & 15 & 4.09 & 47.993 \\
\hline \multirow[t]{3}{*}{2.} & $\mathrm{R}-25 \%-\mathrm{G}-25 \%$ & 20 & $75 \times 75 \times 350$ & 30 & 6 & 6.425 & 37.697 \\
\hline & R-25\%-G-25\% & 20 & $75 \times 150 \times 650$ & 30 & 11 & 5.913 & 49.066 \\
\hline & $\mathrm{R}-25 \%-\mathrm{G}-25 \%$ & 20 & $75 \times 300 \times 1250$ & 30 & 18 & 4.89 & 57.380 \\
\hline \multirow[t]{2}{*}{3.} & R-30\%-G-50\% & 20 & $75 \times 75 \times 350$ & 30 & 7 & 7.491 & 43.955 \\
\hline & R-30\%-G-50\% & 20 & $75 \times 150 \times 650$ & 30 & 13 & 6.980 & 57.91 \\
\hline
\end{tabular}
The formula for cohesive fracture zone length is

$$
C f=\frac{g(\alpha)}{g^{\prime}\left(\alpha_{0}\right)} d_{0}
$$

$g^{\prime}(\alpha)=$ derivative of $g(\alpha)$ with respect to $\alpha$

Failure Loads, Nominal Stresses, Stress Intensity Factors 


\begin{tabular}{|c|c|c|c|c|c|c|c|}
\hline & R-30\%-G-50\% & 20 & $75 \times 300 \times 1250$ & 30 & 21 & 5.69 & 66.768 \\
\hline \multirow[t]{3}{*}{4.} & $\mathrm{R}-50 \%-\mathrm{G}-50 \%$ & 20 & $75 \times 75 \times 350$ & 30 & 8 & 8.558 & 50.214 \\
\hline & R-50\%-G-50\% & 20 & $75 \times 150 \times 650$ & 30 & 15 & 8.046 & 66.767 \\
\hline & R-50\%-G-50\% & 20 & $75 \times 300 \times 1250$ & 30 & 24 & 6.49 & 76.155 \\
\hline
\end{tabular}

\section{Fracture Energy, Cohesive Fracture Zone length}

\begin{tabular}{|c|c|c|c|c|}
\hline $\begin{array}{l}\% \text { Of Robosand and } \\
\text { GGBS }\end{array}$ & Specimen & $\begin{array}{l}\text { Specimen Size } \\
(\mathbf{m m})\end{array}$ & $\begin{array}{l}\mathbf{G}_{f} \\
\mathbf{j} / \mathbf{m}^{2}\end{array}$ & $\begin{array}{l}\mathbf{C}_{f} \\
(\mathbf{m m})\end{array}$ \\
\hline R-0\%-G-0\% & Small & $75 \times 75 \times 350$ & 134.4052 & 26.90961 \\
\hline R-0\%-G-0\% & Medium & $75 \times 150 \times 650$ & 134.4052 & 26.90961 \\
\hline $\mathrm{R}-0 \%-\mathrm{G}-0 \%$ & Large & $75 \times 300 \times 1250$ & 134.4052 & 26.90961 \\
\hline $\mathrm{R}-25 \%-\mathrm{G}-25 \%$ & Small & $75 \times 75 \times 350$ & 204.4738 & 28.57709 \\
\hline $\mathrm{R}-25 \%-\mathrm{G}-25 \%$ & Medium & $75 \times 150 \times 650$ & 204.4738 & 28.57709 \\
\hline $\mathrm{R}-25 \%-\mathrm{G}-25 \%$ & Large & $75 \times 300 \times 1250$ & 204.4738 & 28.57709 \\
\hline R-30\%-G-50\% & Small & $75 \times 75 \times 350$ & 228.6773 & 25.32838 \\
\hline R-30\%-G-50\% & Medium & $75 \times 150 \times 650$ & 228.6773 & 25.32838 \\
\hline R-30\%-G-50\% & Large & $75 \times 300 \times 1250$ & 228.6773 & 25.32838 \\
\hline R-50\%-G-50\% & Small & $75 \times 75 \times 350$ & 327.4485 & 26.67962 \\
\hline R-50\%-G-50\% & Medium & $75 \times 150 \times 650$ & 327.4485 & 26.67962 \\
\hline R-50\%-G-50\% & Large & $75 \times 300 \times 1250$ & 327.4485 & 26.67962 \\
\hline
\end{tabular}




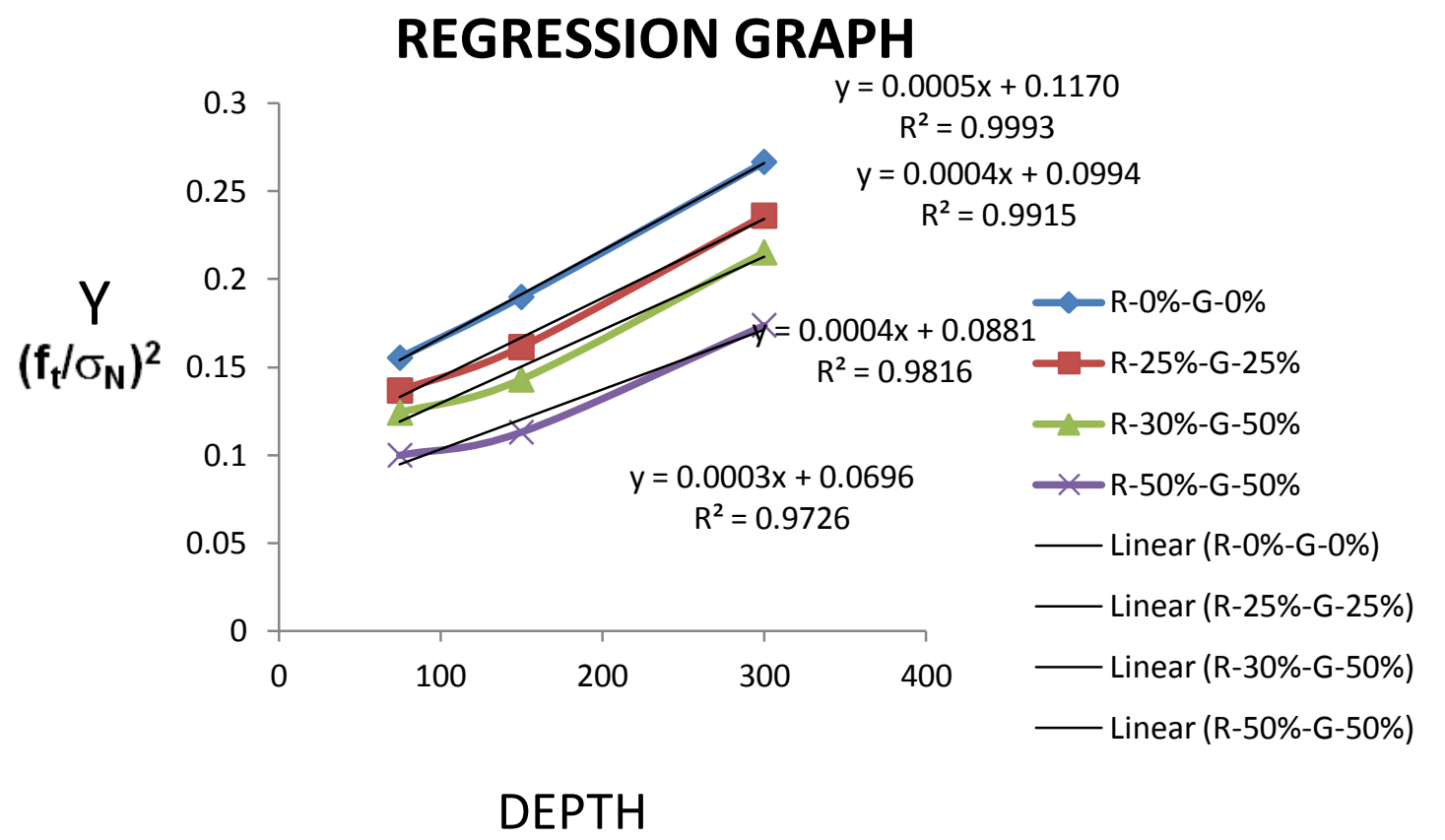

Regression graphs

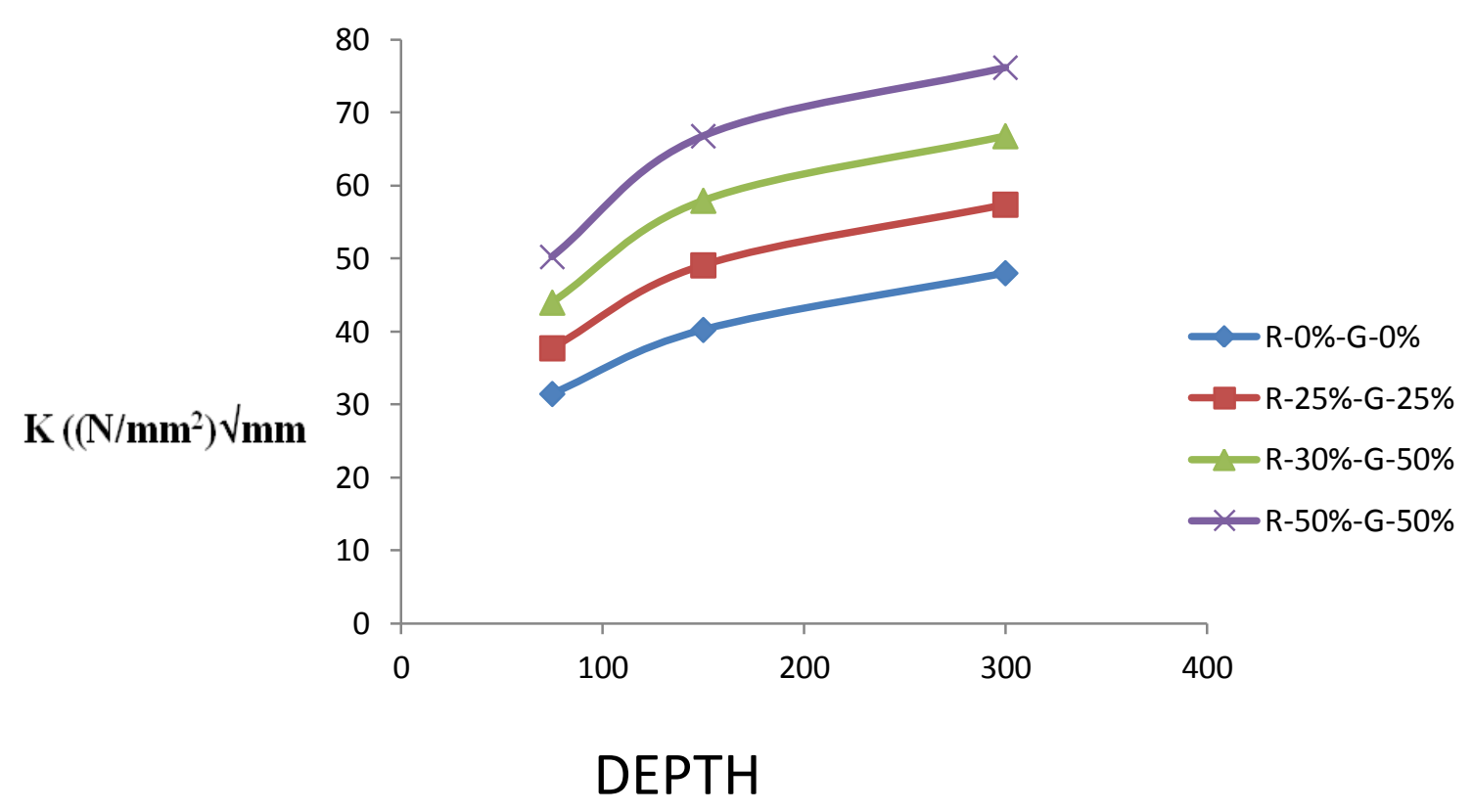

Stress Intensity Factor curves for Depth of beams 

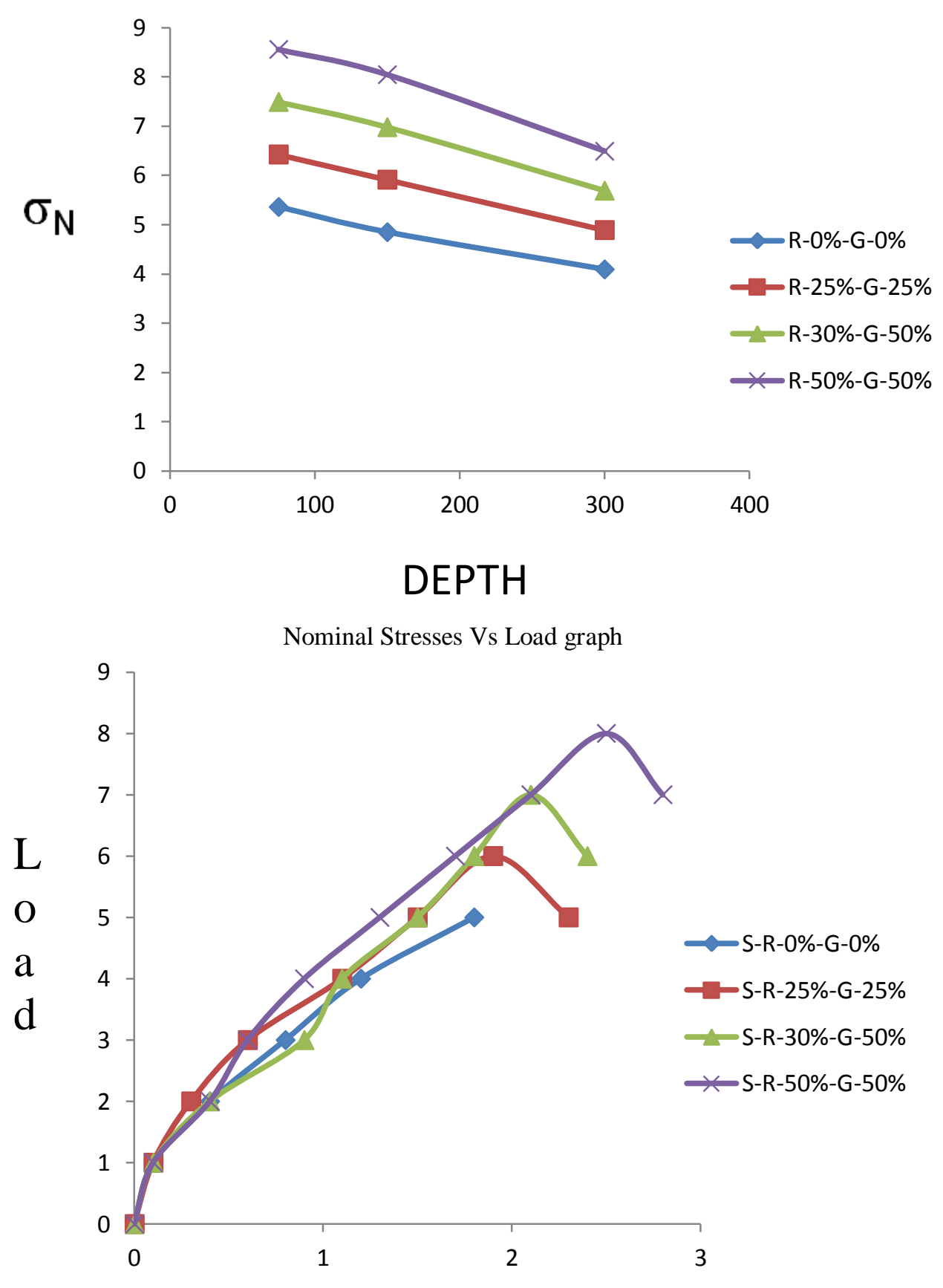

Deflection

Load Vs Displacement graph for Small beams 


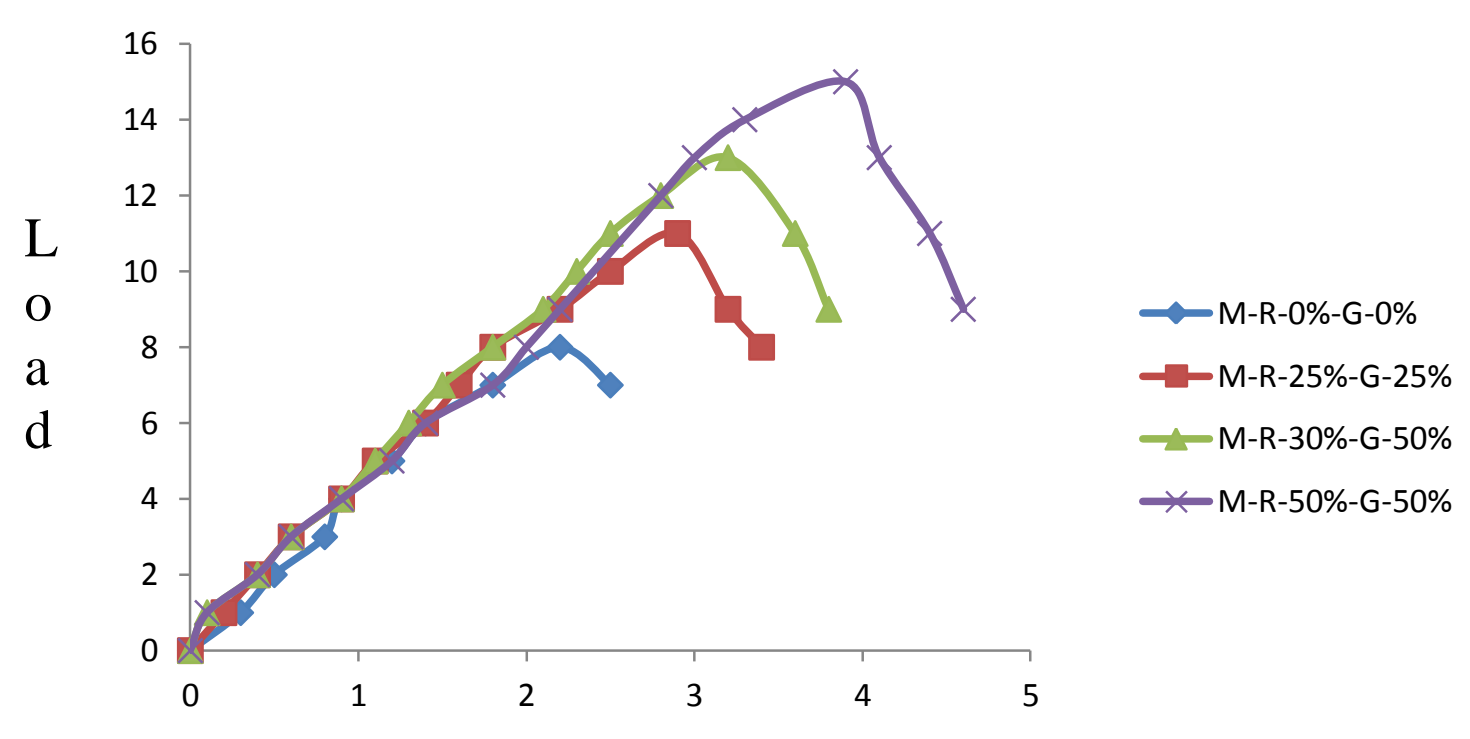

\section{Deflection}

Load Vs Displacement graph for medium beams

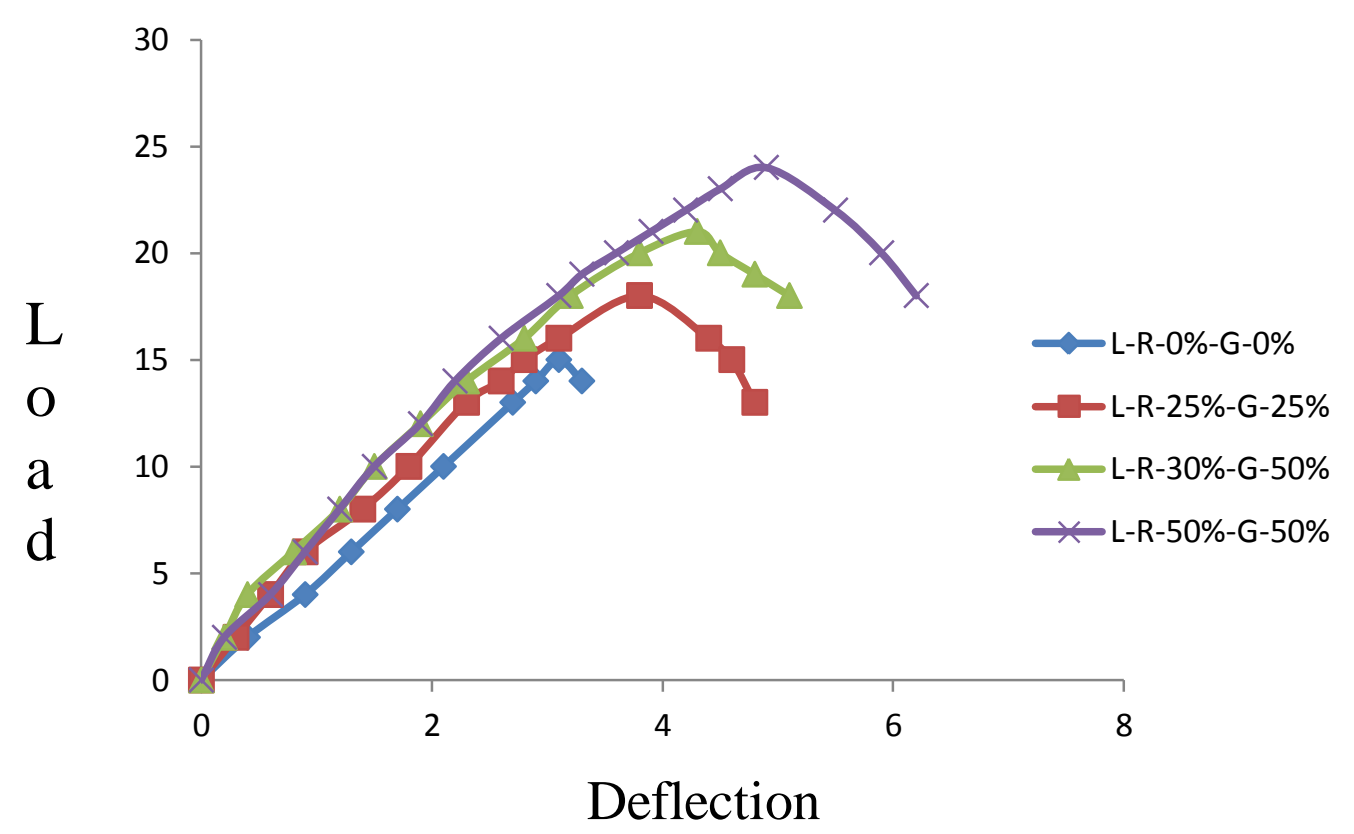

Load Vs Displacement graph for large beams 


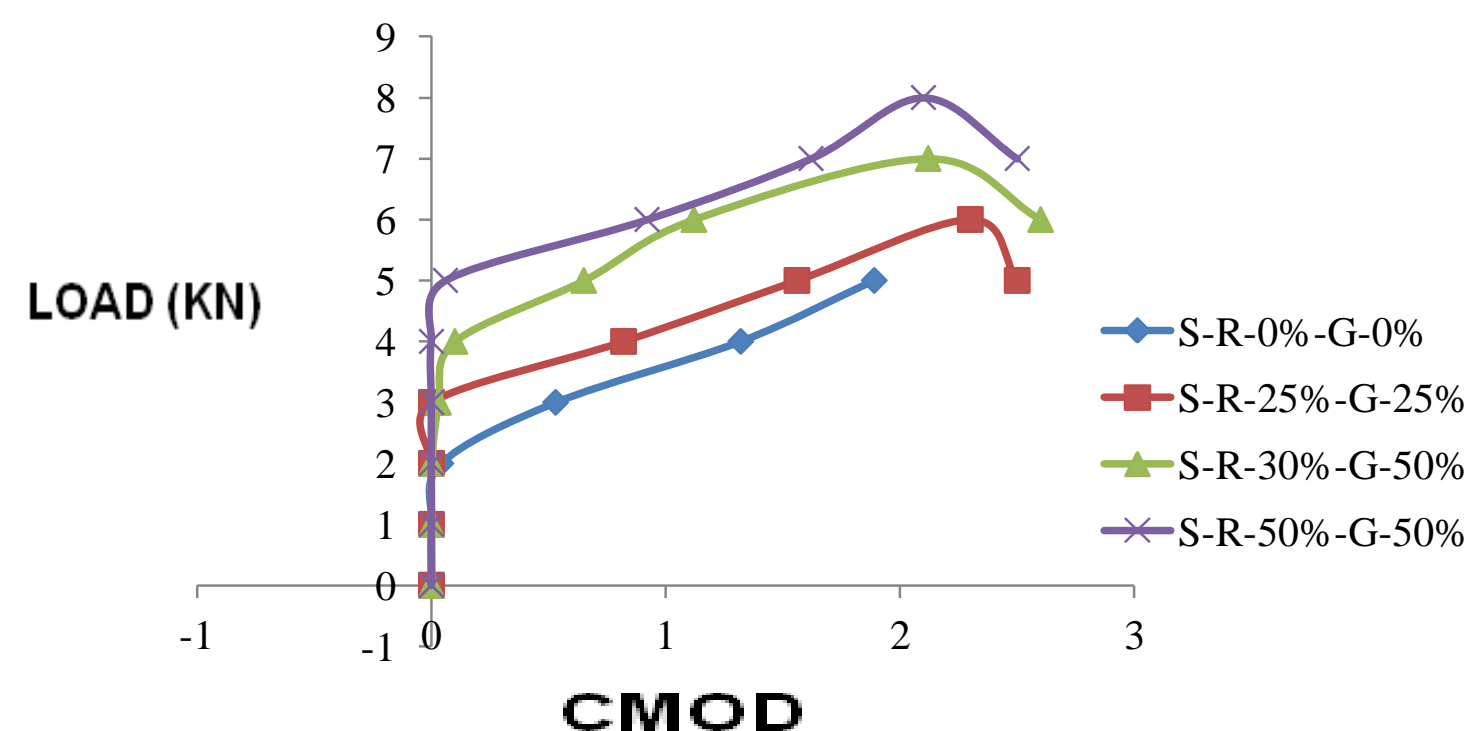

Load Vs CMOD graph for small beams

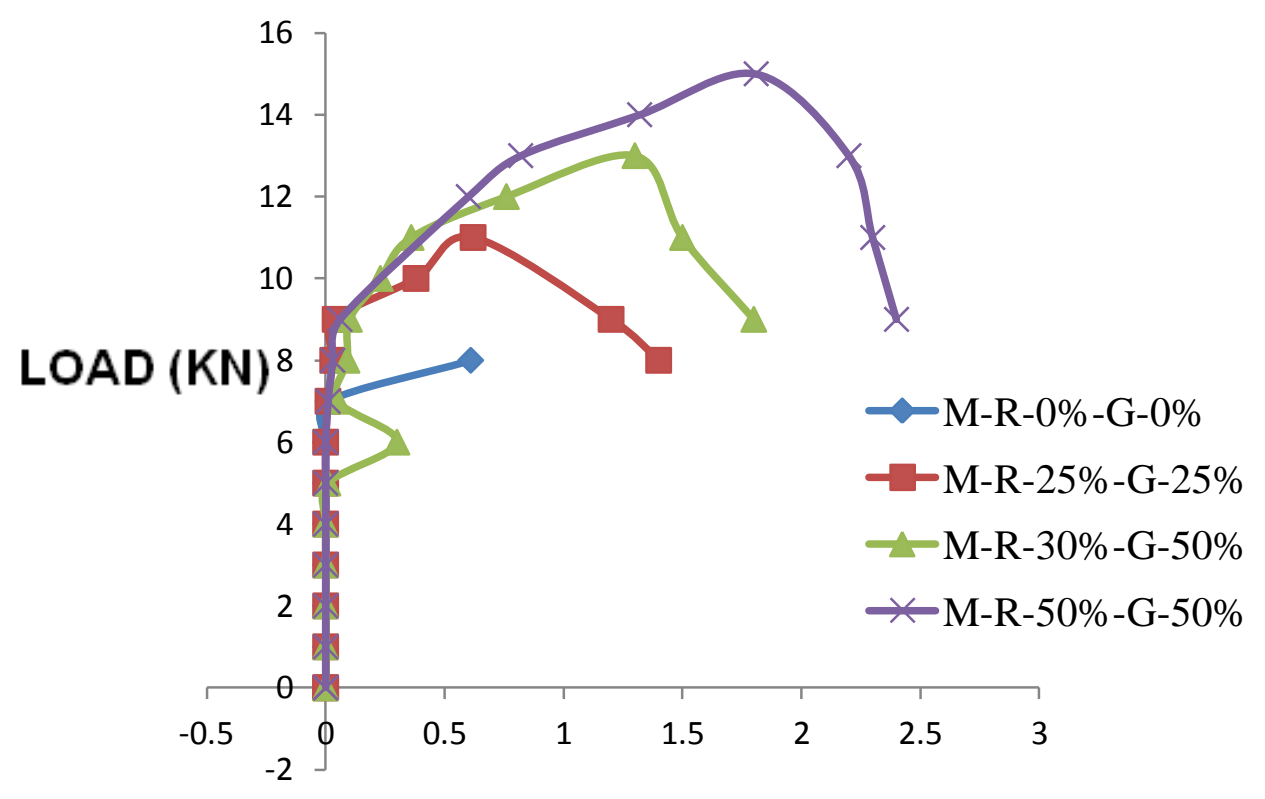

CMOD

Load Vs CMOD graph for MEDIUM beams 


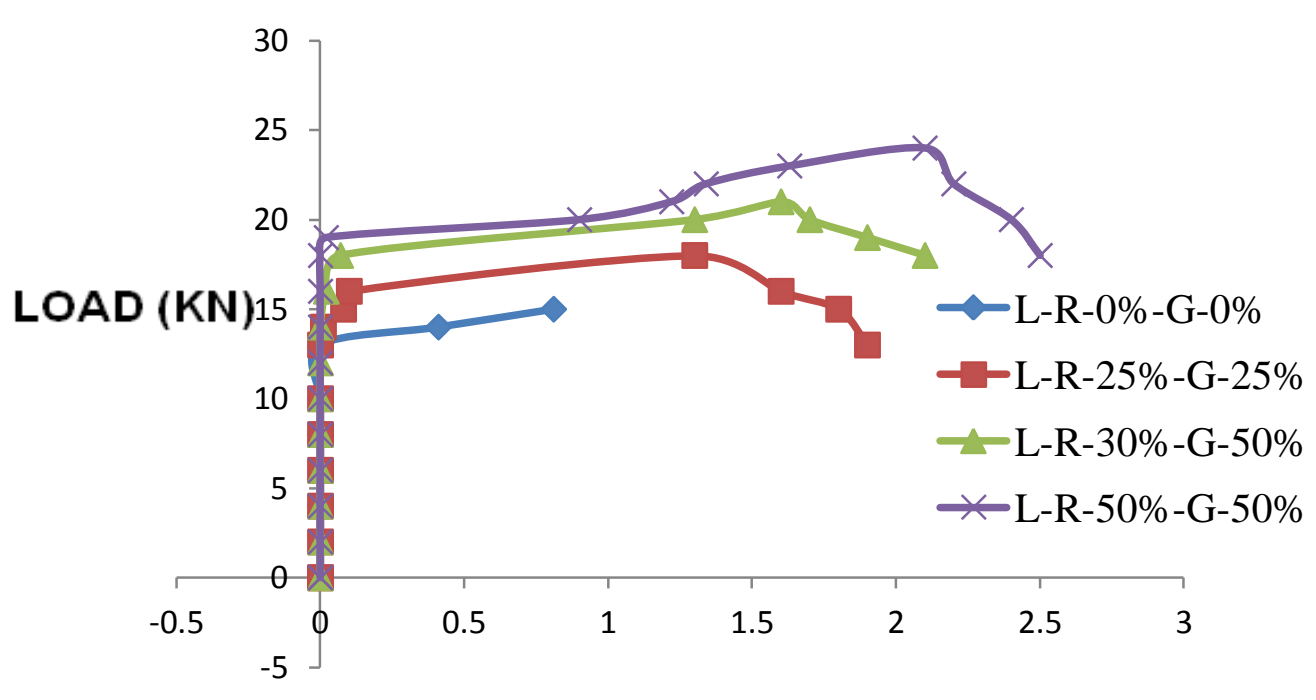

CMOD

Load Vs cmod graph for large beams

\section{BEFORE TESTING}

AFTER TESTING

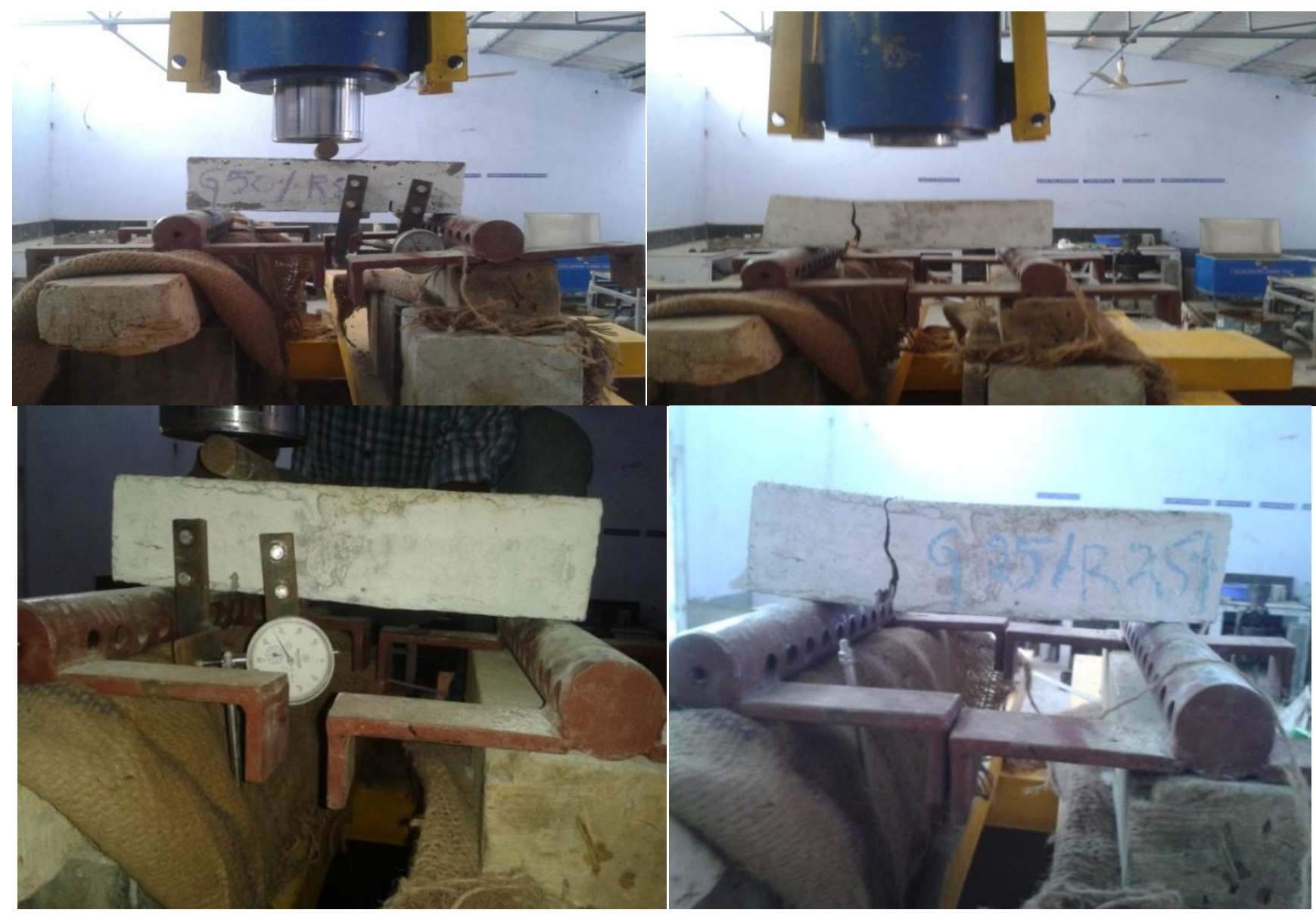



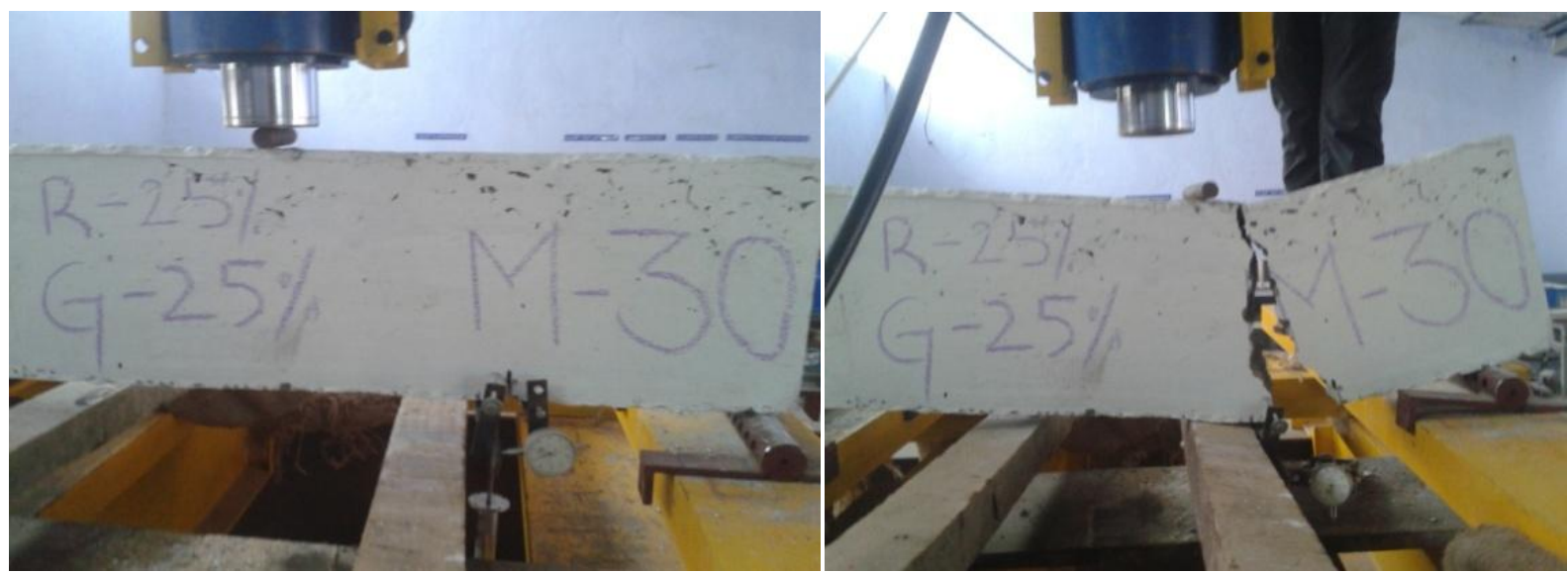

\section{CONCLUSIONS}

Based on the tests on eighteen notched concrete beam specimens, the following conclusions have been drawn:

1. It is observed that, failure stresses (nominal stresses) decreases with increasing of beam sizes.

2. It is also observed that, stress intensity factor increases with increase in beam sizes $\mathrm{f}$

3. It is also observed that, stress intensity factor increases with increase in compressive strength of beams.

4. It is also observed that, Fracture energy decreases with increase in compressive strength of concrete.

5. It is observed that,the stress intensity factor is increases when the beam proportions of GGBS and Robosand are increases.

6. The compressive strength of normal concrete is less than high performance concrete.

7. It is observed that,the Fracture energy is increases when the beam proportions of GGBS and Robosand are increases.

\section{REFERENCES}

[1] In 2008 Dr.T.D.Gunneswararao, Dr.Ch.N.Satish Kumar, Dr.J.girish has done their investigation on "Mixed mode crack propagation through plain concrete".

[2] In 2008 T.D.Gunneswararao, Ch.N.Satish Kumar, Y. Murali Krishna has done their investigation on "Mixed mode crack Fracture energy through Fibre reinforced concrete".

[3] In 2007 Jacinto R. Carmona, Gonzalo Ruiz *, Javier R. del Viso has done their investigation on "Mixed-mode crack propagation through reinforced concrete".

[4] In 2009 M.T. Kazemi* and I. Zakeri has done their investigation on " Mixed-mode crack propagation through reinforced concrete with low volume fraction of ateel fibers."

[5] Bazant, Z.P., "Concrete Fracture Models: Testing and Practice", Eng. Fracture Mech., Vol. 69, (2002), 165-205..

[6] 6.Elices, M., Guinea, G. V. and Planas, J., "Measurement of the Fracture Energy Using Three-
Point Bend Tests: Part 3-Influence of Cutting the P- $\delta$ Tail", Mat. Struct., Vol. 25, (1992), 327-334.

[7] Bazant ZP, Planas J. Fracture size effect in concrete and other quasibrittle materials. Boca Raton: CRC Press; 1998.

[8] J.Ozbolt and H.W. Reinhardt (2000) "Numerical study of mixed mode fracture in concrete structures" Numerical study of mixed mode fracture in concrete structures, Vol.11.

[9] J.C.Galvez, D.A.Cendon and J.Planas (2002)“ Influence of shear parameters on mixed mode fracture of concrete" International journal of Fracture 118: 163-189.

[10] J.C.Galvez, M.Elices, G.V.Guinea and J.Planas (1998)"Mixed mode fracture of concrete under proportional and non proportional loading" International journal of Fracture 94: 267-284.

[11] Parviz Soroushian, Hafez Elyamany, Atef Tlili and Ken Ostowari (1998) “ Mixed mode Fracture properties of Concrete Reinforced with low volume fractions of steel and Polypropylene Fibers" Cement and Concrete Composites 20, 67-78.

[12] Swartz, S.E.,Lu,L.W. and Tang L.D(1998) “ Mixed mode fracture toughness testing of concrete beams in three point bending" Mater. Struct., 21, 33-40.

[13] Indian standard for high strength ordinary Portland cement, IS 8112-1989, Bureau of Indian standards, New Delhi.

[14] Indian Standards for coarse and fine aggregate from natural sources for concrete, IS383:1970, second revision, Bureau of Indian standards, New Delhi.

[15] In 2010, P. N. RAO has done his investigation on High Performance Concrete. The cubes and cylinders are tested for both compressive and tensile strengths.

[16] In 2013, Sumit Kumar has investigate his work of using crushed stone dust as fine aggregate partially or fully with different grades of concrete composites 